\title{
Health related lifestyle in adolescence predicts adult educational level: a longitudinal study from Finland
}

Leena Koivusilta, Arja Rimpelä, Matti Rimpelä

\begin{abstract}
Objective-To assess the relative importance of perceived health and health related lifestyle in adolescence in the production of educational differences.

Design-A longitudinal study: survey data from 1981 and 1985 linked with Educational Registry data from 1993.

Setting-The whole of Finland.

Participants-A representative sample of 476116 and 18 year olds. The follow up rate was $82 \%$.

Measurements and main results-The outcome variable was the attained educational level at age 24 to 30 . Predictive variables described health related lifestyle and health at the age of 16 and 18. Those whose educational level was low at follow up, had in adolescence, a more health compromising lifestyle than those who had reached higher levels. They had placed less emphasis on health promoting behaviours like not smoking, physical exercise, good diet, and dental hygiene. Smoking was the outstanding predictor of attained educational level. Among the health variables, only psychosomatic symptoms predicted high educational levels in girls, and both psychosomatic symptoms and height in boys.

Conclusion-Those who reach a high level of education in adulthood, have had a health enhancing lifestyle already in adolescence, while those reaching only a low level, have had a health compromising lifestyle. Health plays only a small part in the prediction of adult educational level. The results suggest that a health compromising lifestyle, adopted already in adolescence, is an important mechanism from which educational health differences originate.
\end{abstract}

(F Epidemiol Community Health 1998;52:794-801)

Three models-artefactual, causal, and selectional-have been proposed to explain social inequalities in health. According to the selectional model, healthy people are more likely to move up the social hierarchy, and unhealthy people to move down. ${ }^{1}$ The healthy worker effect provides evidence of the existence of health related selection in adult life. ${ }^{2}{ }^{3} \mathrm{How}-$ ever, selection is likely to have its major impact in adolescence, when educational processes leading to adult occupational social classes take place. ${ }^{45}$ In modern specialised occupational structures, entering into paid labour is strongly dependent on educational qualifications. Education determines a person's social position and living conditions and, in addition to status and material resources, it influences the ability and proneness of a person to adopt a healthy way of life. ${ }^{6-8}$

Studies on selection during adolescence are scarce, and have mostly used severe or long term illness as a measure of health. ${ }^{9-12} \mathrm{~A}$ visible illness or handicap may arouse negative attitudes and prejudices, which impede achievement. $^{3413}$ On the other hand, depending on the opportunities offered by the society, severely ill people may be especially motivated to study and thus compensate for their handicaps. ${ }^{14}$

Finland is a welfare state, where free education up to university level is provided for everyone. In a study on 16 year old Finnish youth, chronically ill adolescents were more likely to continue their studies after the compulsory phase than other young people. A good perceived health status was typical of adolescents who had chosen educational careers leading to the highest social positions in society. The health resources of a young person were thus related to the formation of their educational career, but the direction of the selection was different for different health indicators. ${ }^{15} \mathrm{~A}$ positive association between good perceived or general health and good school attainment has also been seen in other studies. ${ }^{1617}$

Another possible mechanism producing social class differences in health could be one where health related lifestyle, or health behaviours, play a central part. Health behaviours develop in adolescence, but have delayed effects in terms of later health. ${ }^{51819}$ A way of life including many health compromising behaviours is typical of adolescents who will eventually achieve a low level of education or remain outside further education after the compulsory phase. ${ }^{20-23}$ Thus, addictive or other health damaging behaviours may be used as markers of a broader lifestyle and attitudes towards society and its values. ${ }^{418} 1924$

Hence, it seems that, already in an early phase of their lives, people begin to follow behavioural and educational trajectories leading to different positions in relation to health and social class in adulthood. Studies on social mobility offer evidence of such an adoption of the way of life of the target social group in adolescence. ${ }^{2526}$ For example, young people who are likely to experience upward social movement are less likely to smoke than young 
Table 1 Formation of the total sample with the response rates of the subsamples in the baseline survey

\begin{tabular}{llllll}
\hline Baseline year & Age at baseline & $\begin{array}{l}\text { Age at } \\
\text { follow up }\end{array}$ & Sex & $\begin{array}{l}\text { Number of } \\
\text { respondents }\end{array}$ & $\begin{array}{l}\text { Response rate } \\
(\%)\end{array}$ \\
\hline 1981 & 18 & 30 & Boys & 519 & 81 \\
& & & Girls & 524 & 88 \\
1981 & 16 & 28 & Boys & 535 & 85 \\
& \multirow{2}{*}{18} & 26 & Girls & 529 & 91 \\
1985 & \multirow{2}{*}{16} & Boys & 402 & 88 \\
& & & Girls & 463 & 77 \\
& & & Boys & 452 & 87 \\
\hline
\end{tabular}

people who remain in the original disadvantaged social positions from one generation to another. ${ }^{18}$ The same phenomenon can be seen at any age in the associations between many health compromising behaviours and short duration of education. ${ }^{27}$

The fact that health related lifestyle in adolescence is involved in a process that simultaneously produces health and social status in adulthood, might also be interpreted as a sign of indirect selection by health. Health related lifestyle would thus be a common predictor of both socioeconomic position and health later in life. The idea of indirect selection seems, however, to need further elaboration. ${ }^{4}{ }^{28}$

Most studies on the association between health or health behaviours and social class are cross sectional or use very short periods of follow up, and a need for longitudinal study designs has been expressed. ${ }^{11} 12152930$ In this study, the survey data on 16 and 18 year olds collected in 1981 and 1985 were linked with information about their highest completed education in 1993. The longitudinal design made it possible to assess the importance of adolescent health and health related lifestyle as predictors of educational level in adulthood. By the ages of 24, 26, 28, and 30 years, adult social class has become established or at least can be strongly anticipated by the attained educational level.

The aim of this study is to assess the relative importance of perceived health and health related lifestyle in adolescence in the creation of differences in educational level in adulthood. The following hypotheses are tested: Perceived health in adolescence predicts the educational level in adulthood (health hypothesis) and health related lifestyle in adolescence predicts the educational level in adulthood (lifestyle hypothesis).

\section{Methods}

This longitudinal study is a part of the Adolescent Health and Lifestyle Survey, which is a national monitoring system of adolescent health and health related lifestyle. Comparable surveys on 12-18 year olds are repeated every second year.

The baseline for this study was the survey data collected in 1981 and 1985, when questionnaires were sent to a national sample of 16 and 18 year old Finns $(n=4761)$. A self administered 12 page questionnaire was sent in February and was followed by two further inquiries to the non-respondents. The sample was drawn from the National Population Register Centre. Responding was voluntary and the purpose of the study was explained in the covering letter.

The follow up of the sample took place in June 1993, when information about their highest completed education, here called attained educational level, was taken from the Educational Registry, kept by Statistics Finland, and linked with the questionnaire data. The completed data set consisted of 3921 persons. There were 840 cases that could not be linked because of missing baseline data. Among them,

Table 2 Associations of health variables with attained educational level in boys and girls: stepwise polychotomous regression analysis. The cumulative odds ratios (COR) with their $95 \%$ confidence intervals (CI) and $p$ values in $\chi^{2}$ tests

\begin{tabular}{|c|c|c|c|c|c|c|}
\hline \multirow[b]{2}{*}{ Independent variable } & \multicolumn{3}{|l|}{ Boys } & \multicolumn{3}{|l|}{ Girls } \\
\hline & $C O R$ & $95 \% C I$ & $p$ valuet & COR & $95 \% C I$ & $p$ valuet \\
\hline Baseline year & & & $\star \star$ & & & NS \\
\hline 1985 & 1.3 & $1.1,1.5$ & & & & \\
\hline 1981 & 1.0 & & & & & \\
\hline $\begin{array}{l}\text { Age at baseline } \\
18\end{array}$ & & & NS & & & NS \\
\hline 16 & & & & & & \\
\hline$\ddagger$ Perceived health & & & $\star \star \star$ & & & $\star \star \star$ \\
\hline Good & 1.7 & $1.3,2.2$ & & 1.9 & $1.5,2.5$ & \\
\hline Moderate & 1.5 & $1.2,1.9$ & & 1.4 & $1.1,1.7$ & \\
\hline $\mathrm{Bad}$ & 1.0 & & & 1.0 & & \\
\hline Height & & & $\star \star \star \star$ & & & * \\
\hline Taller than Q3 & 2.2 & $1.7,2.7$ & & 1.4 & $1.1,1.8$ & \\
\hline From median to Q3 & 1.4 & $1.1,1.8$ & & 1.1 & $0.91,1.4$ & \\
\hline From Q1 to median & 1.7 & $1.3,2.2$ & & 1.1 & $0.91,1.4$ & \\
\hline Shorter than Q1 & 1.0 & & & 1.0 & & \\
\hline Perceived symptoms & & & $\star$ & & & * \\
\hline Rarely & 0.81 & $0.63,1.0$ & & 0.69 & $0.53,0.90$ & \\
\hline Occasionally & 1.1 & $0.88,1.4$ & & 0.90 & $0.73,1.1$ & \\
\hline Often & 1.0 & & & 1.0 & & \\
\hline Tiredness in the daytime & & & NS & & & $\star \star$ \\
\hline No more than school friends & & & & 1.4 & $1.1,1.8$ & \\
\hline More than school friends & & & & 1.0 & & \\
\hline Long term illness or disability & & & NS & & & NS \\
\hline The number of respiratory illness episodes & & & NS & & & NS \\
\hline Physical condition & & & NS & & & NS \\
\hline Feeling oneself active in the morning & & & NS & & & NS \\
\hline
\end{tabular}

$\dagger^{\star} \mathrm{p}<0.05,{ }^{\star \star} \mathrm{p}<0.01,{ }^{\star \star \star} \mathrm{p}<0.001, \mathrm{NS}$ not statistically significant.

$\neq$ For the following variables, adjustments for the baseline year and age at baseline were made. 
Table 3 Associations of lifestyle variables with attained educational level in boys and girls: stepwise polychotomous regression analysis. The cumulative odds ratios (COR) with their 95\% confidence intervals (CI) and $p$ values in $\chi^{2}$ tests

\begin{tabular}{|c|c|c|c|c|c|c|}
\hline \multirow[b]{2}{*}{ Independent variable } & \multicolumn{3}{|l|}{ Boys } & \multicolumn{3}{|l|}{ Girls } \\
\hline & COR & $95 \% C I$ & $p$ valuet & $C O R$ & $95 \% C I$ & $p$ valuet \\
\hline $\begin{array}{l}\text { Baseline year } \\
1985 \\
1981\end{array}$ & & & NS & & & NS \\
\hline Age at baseline & & & NS & & & $\star$ \\
\hline 18 & & & & 1.2 & $1.1,1.5$ & \\
\hline 16 & & & & 1.0 & & \\
\hline$\ddagger$ Smoking & & & $\star \star \star$ & & & $\star \star \star$ \\
\hline Never tried & 2.6 & $1.9,3.5$ & & 5.7 & $4.1,7.9$ & \\
\hline Experimental or occasional & 2.5 & $1.9,3.1$ & & 4.9 & $3.7,6.5$ & \\
\hline $1-9$ cigarettes a day & 1.3 & $0.91,1.8$ & & 2.2 & $1.6,3.1$ & \\
\hline $10+$ cigarettes a day & 1.0 & & & 1.0 & & \\
\hline Alcohol use & & & NS & & & NS \\
\hline Sweating and losing breath during exercise & & & $\star \star \star \star$ & & & $\star \star \star$ \\
\hline Heavily & 2.6 & $1.8,3.6$ & & 2.0 & $1.5,2.8$ & \\
\hline To some extent & 1.6 & $1.2,2.3$ & & 1.7 & $1.3,2.2$ & \\
\hline A little & 1.3 & $0.90,1.8$ & & 1.2 & $0.87,1.5$ & \\
\hline Not at all & 1.0 & & & 1.0 & & \\
\hline Organised physical exercise & & & NS & & & $\star$ \\
\hline Daily & & & & 0.44 & $0.22,0.86$ & \\
\hline Weekly & & & & 1.3 & $0.97,1.7$ & \\
\hline Monthly & & & & 1.1 & $0.88,1.4$ & \\
\hline Rarely & & & & 1.0 & & \\
\hline Unorganised physical exercise & & & $\star$ & & & NS \\
\hline Daily & 0.82 & $0.57,1.2$ & & & & \\
\hline Weekly & 1.1 & $0.84,1.4$ & & & & \\
\hline Monthly & 1.3 & $1.0,1.7$ & & & & \\
\hline Rarely & 1.0 & & & & & \\
\hline Drinking coffee & & & $\star \star \star$ & & & $\star \star \star$ \\
\hline Not daily & 2.0 & $1.6,2.5$ & & 1.9 & $1.5,2.4$ & \\
\hline $1-3$ cups a day & 1.5 & $1.2,1.8$ & & 1.3 & $1.0,1.7$ & \\
\hline 4 cups or more a day & 1.0 & & & 1.0 & & \\
\hline Frequency of brushing teeth & & & $\star \star \star$ & & & $\star \star \star \star$ \\
\hline Several times a day & 2.5 & $1.8,3.4$ & & 4.7 & $1.6,14.0$ & \\
\hline Once a day & 1.7 & $1.3,2.3$ & & 3.0 & $1.1,8.8$ & \\
\hline 2-5 times a week & 1.2 & $0.90,1.7$ & & 1.7 & $0.53,5.2$ & \\
\hline At most once a week & 1.0 & & & 1.0 & & \\
\hline Consumption of snackbar food & & & $\star \star \star$ & & & $\star \star$ \\
\hline Never & 1.7 & $1.1,2.6$ & & 2.6 & $1.5,4.5$ & \\
\hline At most once a week & 1.8 & $1.3,2.5$ & & 2.3 & $1.4,3.8$ & \\
\hline More often & 1.0 & & & 1.0 & & \\
\hline Consumption of sweets & & & $\star \star$ & & & $\star \star$ \\
\hline At most once a week or never & 0.84 & $0.66,1.1$ & & 0.84 & $0.66,1.1$ & \\
\hline About 3-4 times a week & 1.2 & $0.93,1.5$ & & 1.2 & $0.94,1.5$ & \\
\hline Daily & 1.0 & & & 1.0 & & \\
\hline Bedtime & & & * & & & NS \\
\hline Regular & 1.3 & $1.0,1.5$ & & & & \\
\hline Unregular & 1.0 & & & & & \\
\hline Consumption of milk fat & & & NS & & & NS \\
\hline
\end{tabular}

$\dagger^{\star} \mathrm{p}<0.05,{ }^{\star \star} \mathrm{p}<0.01,{ }^{\star \star \star} \mathrm{p}<0.001, \mathrm{NS}$ not statistically significant

$\ddagger$ For the following variables, adjustments for the baseline year and age at baseline were made.

the proportion of people with only a basic education or with a low educational level was statistically significantly higher $(p<0.001)$ than among those who had complete data in both phases of data collection. The linking of data was done so that the identification numbers of study subjects were not at any stage available to the researchers. Before the data linking, a contract was signed between Statistics Finland and the researchers, which stated the rights and duties of both contracting parties, especially the obligation to maintain secrecy.

Table 1 shows the formation of the total sample with the response rates at follow up.

A four category dependent variable attained educational level at follow up, was based on the classification of educational level used in Finnish educational statistics. The categories were: basic education (9 years of school), lower middle education (10-11 years of school), upper middle education (12 years of school), high education (at least 13 years of school).

The independent variables (Appendix) were divided into those describing health (table 2) and those describing health related lifestyle (table 3). Most of the health variables are indi- cators of self assessed health, such as perceived health, perceived symptoms, tiredness in the daytime, the number of respiratory illness episodes, physical condition, and feeling oneself active in the morning. Long term illness or disability is, in general, diagnosed by a doctor, and height is based on numerical measurement. The variables describing health related lifestyle consist of smoking, alcohol use, three measures of the amount of physical exercise, dental hygiene, bedtime, and consumption of coffee, snackbar food, sweets, and milk fat.

\section{STATISTICAL ANALYSES}

The dependent variable consisted of more than two categories, and thus its associations with the independent variables were analysed using stepwise polychotomous logistic models. ${ }^{31} 32$ Because of the ordinal nature of the dependent variable, cumulative logistic models were used. In the stepwise selection process, at every step, the variable showing the strongest association with the dependent variable was chosen for the model. The inclusion of this "most important" variable may render insignificant some other 
Table 4 The final model for boys: the relative significance of health and lifestyle variables for attained educational level: stepwise polychotomous regression analysis. The cumulative odds ratios (COR) with their $95 \%$ confidence intervals (CI) and $p$ values in $\chi^{2}$ tests $t$

\begin{tabular}{|c|c|c|c|}
\hline Independent variable & COR & $95 \% C I$ & $p$ value $\neq$ \\
\hline $\begin{array}{l}\text { Baseline year } \\
1985 \\
1981\end{array}$ & & & NS \\
\hline Age at baseline & & & $\star$ \\
\hline 18 & 1.2 & $1.0,1.5$ & \\
\hline 16 & 1.0 & & \\
\hline §Smoking & & & $\star \star \star \star$ \\
\hline Never tried or not daily & 2.9 & $2.3,3.6$ & \\
\hline 1-9 cigarettes a day & 1.5 & $1.1,2.1$ & \\
\hline $10+$ cigarettes a day & 1.0 & & \\
\hline Sweating and losing breath during exercise & & & $\star \star \star \star$ \\
\hline Heavily or to some extent & 1.8 & $1.4,2.1$ & \\
\hline A little or not at all & 1.0 & & \\
\hline Drinking coffee & & & $\star \star \star$ \\
\hline Not daily & 1.7 & $1.4,2.0$ & \\
\hline Daily & 1.0 & & \\
\hline Frequency of brushing teeth & & & $\star \star \star$ \\
\hline Several times a day & 2.0 & $1.6,2.6$ & \\
\hline Once a day & 1.5 & $1.2,1.8$ & \\
\hline At most 5 times a week & 1.0 & & \\
\hline Height & & & $\star \star \star$ \\
\hline Taller than Q3 & 1.9 & $1.5,2.4$ & \\
\hline From Q1 to median & 1.4 & $1.2,1.7$ & \\
\hline Shorter than Q1 & 1.0 & & \\
\hline Consumption of sweets & & & $\star \star$ \\
\hline About 3-4 times a week & 1.4 & $1.1,1.6$ & \\
\hline Less than once a week/daily & 1.0 & & \\
\hline Consumption of snackbar food & & & $\star \star \star \star$ \\
\hline Never or at most once a week & 1.8 & $1.3,2.4$ & \\
\hline More often & 1.0 & & \\
\hline Perceived symptoms & & & $\star \star \star$ \\
\hline Rarely & 0.68 & $0.56,0.83$ & \\
\hline Occasionally or often & 1.0 & & \\
\hline Unorganised physical exercise & & & $\star \star$ \\
\hline Monthly & 1.3 & $1.1,1.6$ & \\
\hline Daily/weekly/rarely & 1.0 & & \\
\hline Bedtime & & & $\star$ \\
\hline Regular & 1.3 & $1.0,1.5$ & \\
\hline Unregular & 1.0 & & \\
\hline Perceived health & & & NS \\
\hline
\end{tabular}

†Variables appear in their order of selection into the model.

$\ddagger^{\star} \mathrm{p}<0.05,{ }^{\star \star} \mathrm{p}<0.01,{ }^{\star \star \star} \mathrm{p}<0.001$, NS not statistically significant.

$§$ For the following variables, adjustments for the baseline year and age at baseline were made.

candidate variable, which may partly reflect the same underlying characteristic.

The course of analyses was such that univariate associations of independent variables with educational level were first examined using $\chi^{2}$ test. Then a stepwise procedure was used to select, from the statistically significant variables, the ones that showed independent associations with the attained educational level. This procedure was carried out separately for health and lifestyle variables. Then, to find out the relative significance of health variables and lifestyle variables, a final model was formed by including the two above selected sets of independent variables in a stepwise analysis. The confounding variables, baseline year and age at baseline, were forced into the models before the selection of independent variables. All the analyses were made separately for boys and girls.

The cumulative odds ratios (CORs) with $95 \%$ confidence intervals $(\mathrm{CI})$ were calculated for the variables showing statistically significant explanatory power. It is assumed that the differences between the categories of independent variables appear as shifts in the percentage distribution of the independent variable, measured on an ordinal scale. CORs quantify these shifts. For every independent variable, the category that was expected to have the least probability of belonging to high educational levels was taken as the reference group for the COR. In the final models, categories with approximately the same COR were combined. The logistic regression functions were computed using only the cases that had values for every variable. The proportions of missing cases (that is, at least one variable having a missing value) in the final model were $8 \%$ for boys and $5 \%$ for girls. The variables affected by missing values were perceived health (a value missing in $0.1 \%$ cases of the entire study material), height $(1.1 \%)$, perceived symptoms $(2.0 \%)$, tiredness in the daytime $(0.8 \%)$, respiratory illnesses $(0.8 \%)$, physical condition $(0.3 \%)$, feeling oneself active in the morning $(0.3 \%)$, smoking $(0.1 \%)$, alcohol use $(0.5 \%)$, sweating on exercise $(1.3 \%)$, organised exercise $(3.5 \%)$, unorganised exercise $(1.1 \%)$, coffee $(0.8 \%)$, dental hygiene $(0.2 \%)$, snackbar food $(0.3 \%)$, sweets $(0.7 \%)$, bedtime $(0.3 \%)$, and milk fat $(0.4 \%)$. Decisions regarding statistical significance were made at the $5 \%$ risk level. The analyses were carried out using the PR program in the statistical software BMDP. ${ }^{33}$

\section{Results}

Boys and girls had almost equally often reached the highest educational level $(18 \%$ and $20 \%$, respectively), but girls (44\%) had more often than boys (29\%) had upper middle education. A greater proportion of boys (54\%) than of girls $(36 \%)$ was found in the two lowest educational categories $(\mathrm{p}<0.001)$.

In boys, three health indicators were statistically significant, in both univariate and stepwise analyses. Of these, height was the first to be selected and was thus most closely associated with the attained educational level (table 2 ). The association was almost linear, in that the educational level rose with height. Also, good and moderate perceived health predicted a high educational level. There was a weak opposite association between educational level and perceived symptoms.

In girls, four health variables were statistically significant in stepwise analysis. Good perceived health was the most important health predictor of a high educational level (table 2). There was an opposite association between educational level and perceived symptoms. The highly educated girls had not felt unusually tired in the daytime. Girls belonging to the tallest height quartile had most often reached high levels of education. Physical condition $(p<0.01)$ and long term illness or disability $(\mathrm{p}<0.01)$ were significantly associated with educational level, but only in univariate analysis. Good physical condition characterised the girls who had attained higher levels of education (very good $v$ not good: $\mathrm{COR}=1.7$ with $\mathrm{CI}$ $1.2,2.4$, good $v$ not good: $\mathrm{COR}=1.2$ with $\mathrm{CI}$ $1.0,1.5)$. Also, not having a long term illness was typical of them (no $v$ yes: $\mathrm{COR}=1.4$ with CI $1.1,1.9$ ).

In boys, after the stepwise selection of independent variables, eight lifestyle variables were statistically significant (table 3), the strongest one being smoking. Educational level and the number of cigarettes smoked were negatively associated. Taking part in organised physical exercise, alcohol use, and consumption of milk 
Table 5. The final model for girls: the relative significance of health and lifestyle variables for attained educational level: stepwise polychotomous regression analysis. The cumulative odds ratios (COR) with their $95 \%$ confidence intervals (CI) and $p$ values in $\chi^{2}$ tests $t$

\begin{tabular}{|c|c|c|c|}
\hline Independent variable & $C O R$ & $95 \% C I$ & $p$ value $\neq$ \\
\hline $\begin{array}{l}\text { Baseline year } \\
1985 \\
1981\end{array}$ & & & NS \\
\hline Age at baseline & & & $\star$ \\
\hline 18 & 1.2 & $1.0,1.4$ & \\
\hline 16 & 1.0 & & \\
\hline §Smoking & & & $\star \star \star$ \\
\hline Never tried or not daily & 5.7 & $4.3,7.5$ & \\
\hline $1-9$ cigarettes a day & 2.3 & $1.7,3.3$ & \\
\hline $10+$ cigarettes a day & 1.0 & & \\
\hline Frequency of brushing teeth & & & $\star \star \star$ \\
\hline Several times a day & 3.1 & $2.0,4.8$ & \\
\hline Once a day & 2.0 & $1.3,3.1$ & \\
\hline At most 5 times a week & 1.0 & & \\
\hline Sweating and losing breath during exercise & & & $\star \star \star$ \\
\hline Heavily or to some extent & 1.7 & $1.4,2.0$ & \\
\hline A little or not at all & 1.0 & & \\
\hline Drinking coffee & & & $\star \star \star$ \\
\hline Not daily & 1.6 & $1.4,1.9$ & \\
\hline Daily & 1.0 & & \\
\hline Consumption of sweets & & & $\star \star$ \\
\hline About 3-4 times a week & 1.3 & $1.1,1.6$ & \\
\hline Less than once a week/daily & 1.0 & & \\
\hline Consumption of snackbar food & & & $\star \star \star$ \\
\hline Never or at most once a week & 2.4 & $1.5,4.0$ & \\
\hline More often & 1.0 & & \\
\hline Organised physical exercise & & & $\star$ \\
\hline Daily & 0.46 & $0.23,0.90$ & \\
\hline More seldom & 1.0 & & \\
\hline Perceived symptoms & & & $\star$ \\
\hline Rarely & 0.80 & $0.65,0.98$ & \\
\hline Occasionally or often & 1.0 & & \\
\hline Perceived health & & & NS \\
\hline Tiredness in the daytime & & & NS \\
\hline Height & & & NS \\
\hline
\end{tabular}

†Variables appear in their order of selection into the model.

$\ddagger^{\star} \mathrm{p}<0.05,{ }^{\star \star} \mathrm{p}<0.01,{ }^{\star \star \star} \mathrm{p}<0.001$, NS not statistically significant.

§For the following variables, adjustments for the baseline year and age at baseline were made.

fat were significant only in univariate analysis: high levels of education were typical of boys who had taken part moderately in organised physical exercise $(\mathrm{p}<0.001$; daily $v$ rarely: $\mathrm{COR}=1.5$ with CI $0.97,2.2$, weekly $v$ rarely: $\mathrm{COR}=1.8$ with CI $1.5,2.3$, monthly $v$ rarely: $\mathrm{COR}=1.3$ with CI 1.0, 1.6), whose alcohol use had been controlled or minor $(p<0.001$; none $v$ uncontrolled: $\mathrm{COR}=2.1$ with $\mathrm{CI} 1.5,2.9$, controlled $v$ uncontrolled: $\mathrm{COR}=2.9$ with CI 2.1 , 4.0, less controlled $v$ uncontrolled: $\mathrm{COR}=2.0$ with CI 1.5, 2.6) and who had consumed milk fat moderately $(\mathrm{p}<0.001$; minor use $v$ heavy use: $\mathrm{COR}=1.0$ with $\mathrm{CI} 0.65,1.6$, medium use $v$ heavy use: $\mathrm{COR}=1.4$ with CI $1.2,1.7)$.

In girls, seven lifestyle variables were statistically significant in the stepwise analysis (table 3). Smoking was clearly the most outstanding predictor of educational level, with the probability of high educational level rising linearly as the number of cigarettes smoked decreased. Three variables were significant in univariate analysis only. High levels of education were typical of girls, whose bedtime was regular $(\mathrm{p}<0.001$; regular $v$ irregular: $\mathrm{COR}=1.6$ with CI 1.4, 2.0), who had taken part in unorganised physical exercise $(\mathrm{p}<0.001$; daily $v$ rarely: $\mathrm{COR}=1.7$ with CI $1.2,2.3$, weekly $v$ rarely: $\mathrm{COR}=1.9$ with CI $1.5,2.4$, monthly $v$ rarely: $\mathrm{COR}=1.6$ with $\mathrm{CI} 1.3,2.0$ ), and who had not used alcohol in an uncontrolled way $(\mathrm{p}<0.001$; none $v$ uncontrolled: $\mathrm{COR}=2.9$ with $\mathrm{CI} 1.9$, 4.4, controlled $v$ uncontrolled: $\mathrm{COR}=3.4$ with CI 2.3, 5.1, less controlled $v$ uncontrolled; $\mathrm{COR}=1.8$ with CI $1.2,2.7$ ).
KEY POINTS

- Health compromising lifestyle in adolescence predicts a low educational level in adulthood.

- Health enhancing lifestyle in adolescence predicts a high educational level in adulthood.

- Selection by health related lifestyle is one possible mechanism in producing socioeconomic health differences.

The next step was to include the above selected independent variables in a stepwise procedure to find out the relative significance of health and lifestyle variables for the attained educational level. In both sexes, lifestyle had a central role. In boys, height and the frequency of perceived symptoms were the only health variables to be selected into the model, while in girls, the frequency of perceived symptoms was the only such variable (table 4).

Baseline year was associated with the attained educational level only in the model of health variables in boys. The 1985 sample had reached a higher level of education than the 1981 sample. Age at baseline was significant in the model of lifestyle variables in girls. Those who were 18 years old at baseline had reached a higher level of education than those who were 16 years old at baseline. In the two final models, in both sexes, age at baseline was significant in that those who were 18 years old at baseline had reached a higher level of education than those who were 16 years old at baseline (table 5 ).

\section{Discussion}

The study gave strong support to the lifestyle hypothesis, while the health hypothesis did not get much support. People who had ended up with lower educational levels had, in adolescence, a more health compromising lifestyle than those who had reached higher levels. They seemed to have placed less emphasis on health promoting behaviours, such as physical exercise, good diet, non-smoking, and maintenance of oral health. It has been found that the road leading to an unstable career in young adulthood includes many kinds of problem behaviour in adolescence, and that the roots of adult lifestyles are found in patterns of adjustment in childhood and adolescence. ${ }^{34}{ }^{35}$ Thus, it seems likely that the adoption of lifestyle of the target social group had already taken place by the age of $16 .^{184-26}$

The variable with outstanding significance for educational level in both sexes, was smoking. Its central role in poor school attainment, disaffection with school, reluctance to take part in further education after the compulsory phase, and an overall adoption of non-conventional values in society has been confirmed also in other studies on adolescents. ${ }^{18-21}$ Smoking has been considered a marker of a broader lifestyle, typical of which are the rejection of an achievement ideology and the adoption of an anti-school orientation, leading to accentuated and early adoption of some adult-like behaviours. ${ }^{42136}$ 


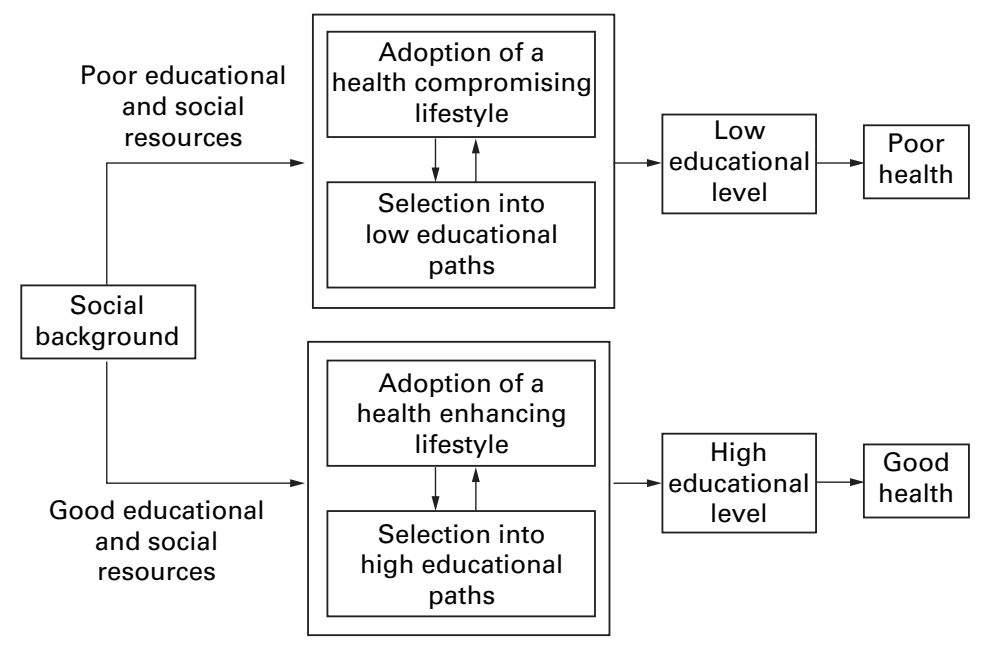

Time

Childhood

Adolescence

Adulthood

Figure 1 Educational career from childhood to adulthood.

Alcohol use was highly significantly associated with educational level in the univariate analyses, but was not selected into the models. This follows from the way in which the stepwise method at every step selects the most significant predictor from the set of possibly intercorrelated variables. Thus, the inclusion of smoking into the model renders variable alcohol use insignificant. Although these two behaviours are closely associated with each other, it is also possible that they have different bases in adolescence. Among Finnish youth, there are nowadays two different dimensions to addictive behaviour. ${ }^{37} 38$ On the traditional dimension, smoking and drinking go together, with smoking being the stronger determinant and usually almost always linked to drinking. The modern dimension involves use of alcohol, but not smoking. A systematic increase in the group that drinks but does not smoke has been found. ${ }^{37}$

In boys, monthly physical exercise was associated with high levels of education, while in girls, taking part in daily physical exercise predicted attaining lower levels of education. It is possible that, for boys, it is a question of taking part in team sports, an activity that is highly valued within the adolescent subculture. ${ }^{39}$ In girls, those taking a very active part in sports may have made a choice between an educational career and sports. Moreover, several aspects of diet were associated with attained educational level in both sexes. A high frequency of eating snackbar food was related to low levels of education. This may indicate a way of life that is oriented towards leisure and peers.

In some important variables, like smoking, the associations with attained educational level were weaker in boys than in girls. Boys in each subsample answered the baseline surveys less enthusiastically than girls, especially in 1985 . The non-responders had more often had only basic education or had reached lower educational levels than the responders. The same phenomenon has been detected in other health studies. In young men, non-response has been associated with poor school performance, and negative health behaviour. ${ }^{40}$ This kind of selection would mean that the associations found in boys were weaker than they would have been had the response rate been higher.

Concerning health variables, the association between boys' height and educational level could be interpreted as a sign of selection by health. Height at a young age may be an indicator of health, which influences social position, especially in men. ${ }^{41-44}$ However, several implications have been connected with height. It may, for example, be considered a marker of living conditions, which predict both adult health and adult social position. ${ }^{42} 4546$ There is also some evidence that early growth and an early maturation process are associated with intellectual development, and this could be one explanation for the positive association between boys' height and educational level. ${ }^{47}$ Height may also be a factor in forming people's life careers through its sociological implications. ${ }^{4}$

Perceived symptoms were of some importance in that boys and girls with more symptoms were more likely to have reached high levels of education than those with fewer symptoms. This may indicate that putting effort into making good progress in education, taxes a person's resources. In models that included only health variables, good perceived health was associated with reaching high levels of education. Thus, overall perceived health and the frequency of different symptoms reflect different aspects of health, the former probably referring to general well being and the satisfaction given by the ability to fulfill the expectations set for young people in a society where education is highly valued. Symptoms, on the other hand, may be more closely related to the everyday efforts needed in striving for educational success.

With the available data, we could not examine the existing socioeconomic health differences in adulthood. However, we assume that by studying health related lifestyles in adolescence we are gaining information about the mechanism that generates these differences, as particular behaviours and lifestyles, which develop in adolescence, have implications both for subsequent social position and for health in early adulthood. ${ }^{418} 19$ In the Finnish welfare society, where an acceptable standard of living has been guaranteed for everyone, sickness does not necessarily cause exclusion from social or economic welfare, but to be driven into a lifestyle which, in the long run, leads to illness and low educational resources, may eventually cause marginalisation in many spheres of life. ${ }^{48}$ All in all, selection by health related lifestyle seems to offer a more fruitful starting point for explaining the mechanism of development of health inequalities than does selection by health.

In this paper, we confined ourselves to studying the associations between adolescent lifestyle and health and educational level in adulthood. However, in the process during 
which health inequalities are being formed, the early determinants of lifestyle and educational level are important, especially the social background and social relations of the childhood family. ${ }^{49}$ Of great importance are also other selection mechanisms, through which the lifestyle is adopted, and which influence educational decisions. Among these are, for example, social relations in peer groups and factors related to school, starting from the very first grade.

In figure 1 , we propose a model that will be important in further studies, to search for more profound knowledge about the mechanism involved in how education and health related lifestyle reinforce each other during development from adolescence to adulthood. In this model, a central role is given to socioeconomic background, including parents' education and occupation, family structure, and social relations. Regional factors are also considered, because they influence educational supply. These background factors are regarded as resources available for entering different educational paths early in life, and as modifiers of the associations between lifestyle and educational path. As in Lundberg's "unhealthy life career hypothesis", poor childhood living conditions would be a principal factor starting a chain of unhealthy living conditions, leading to a low level of education, restricted opportunities on the labour market and, thus, to poor living conditions in adulthood with increased illness risks. ${ }^{51}$ The model makes it possible to focus attention, on the one hand, on the lifestyles of people, and, on the other hand, on structural factors, which are associated with social class differences in the society. To explain selection into high and low educational paths, health related lifestyle is divided into health compromising behaviours and health enhancing behaviours. ${ }^{52}$

\section{Appendix \\ Independent variables \\ Health}

- Perceived health at the time of inquiry: good (combines classes very good and good), moderate, bad (combines classes very bad and bad).

- Height: four categories, using the distribution quartiles as cutpoints. Cutpoints were calculated separately for each combination of sex and age.

- Perceived symptoms during the preceding six months: a sum-index constructed of the frequency (seldom or never, occasionally, quite often, often or continuously; points from 1 to 4, respectively) of feeling eight symptoms (abdominal pains, anxiety, irritability or fits of anger, difficulties in sleeping, headache, tremor of hands, fatigue or weakness, fits of dizziness). Cutpoints, which were calculated separately in 1981 and 1985 were set to leave at most $30 \%$ of respondents in the lower and upper ends of the distribution.

- Tiredness in the daytime: no more than school friends, more than school friends.
- Long term illness or disability that disturbs everyday life: no, yes. The most common illnesses were asthma and allergy and rhinitis.

- The number of respiratory illness episodes during the preceding six months: none, one, at least two.

- Physical condition at the time of inquiry: very good, good, not good (combines classes moderate, bad and very bad).

- Feeling oneself active in the morning: every morning or quite often, occasionally, seldom or never.

\section{Health related lifestyle}

- Smoking: never tried, experimental or occasional (had smoked at most 50 times, but did not smoke daily), 1-9 cigarettes a day, 10+ cigarettes a day.

- Alcohol use: none (do not drink alcohol or drink at most once a year, but never get drunk), controlled drinking (drink but never get drunk), less controlled drinking (drink at most twice a month and get drunk at most once a month/drink at least once a week, but get drunk more seldom than once a month), uncontrolled drinking (drink at least once a week and get drunk at least once a month).

- Physical exercise was measured with three variables

(i) The amount of sweating and losing one's breath during exercise: heavily, to some extent, a little, not at all (or does not take part in exercise).

(ii) Organised physical exercise was obtained by summarizing, for each respondent, the total frequency of taking part in exercise organised by, (a) schools or workplaces (physical training lessons were excluded), (b) sports clubs, and (c) other associations or clubs. Classification was: daily, weekly (at least twice a week, but less frequently than daily), monthly (at least once a month, but not more often than once a week), rarely (less frequently than once a month or no exercise at all).

(iii) Unorganised physical exercise is a measurement of exercise done alone or with friends or members of the family: classification as above.

- Drinking coffee: not daily, 1-3 cups a day, 4 cups or more a day.

- Dental hygiene was measured as the frequency of brushing teeth: several times a day, once a day, 2-5 times a week, at most once a week (or never).

- Consumption of snackbar food: never, at most once a week, more often.

- Consumption of sweets: at most once a week (or never), about 3-4 times a week, daily.

- Bedtime: regular, irregular.

- Consumption of milk fat was a combination variable of the type of milk a person drinks and the type of fat spread on bread. The three categories were: minor use (do not drink milk or drink skimmed milk and do not use fat on bread, or use margarine or comparable types of spread), medium use (do not suit either the first or the third category), heavy use of milk fat (use whole milk and mostly butter). 
1. Blane D. An assessment of the Black Report's explanations of health inequalities. Sociol Health Illness 1985;7:423-45.

2 Ostlin P. Negative health selection into physically light occupations. F Epidemiol Community Health 1988;42:152-6.

3 Bartley M. Unemployment and health: selection or causation - a false antithesis? Sociol Health Illness 1988;10: $41-67$

4 West P. Rethinking the health selection explanation for health inequalities. Soc Sci Med 1991;32:373-84.

5 West P. Inequalities? Social class differentials in health in British youth. Soc Sci Med 1988;27:291-6. 6 Halsey AH, Heath AF, Ridge JM. Origins and destinations. Clarendon Press, 1980

7 Timmons G. Education, industrialization, and selection. London: Routledge, 1988.

8 Elo IT, Preston SH. Educational differentials in mortality: United States 1979-85. Soc Sci Med 1996;42:47-57.

9 Wadsworth MEJ. Serious illness in childhood and its association with later-life achievement. In: Wilkinson RG, ed. Class and health. Research and longitudinal data. London: Tlass and health.

10 Lundberg O. Class position and health: Social causation or social selection? Stockholm: Swedish Institute for Social Research, University of Stockholm. Meddelande 8/1988.

11 Pless IB, Power C, Peckham CS. Long-term psychosocial sequelae of chronic physical disorders in childhood. Pediat rics 1993;91:1131-6.

12 Hirst M. Careers of young people with disabilities between ages 15 and 21 years. Disability, Handicap and Society 1987; 2:61-74.

13 Jenkins R. Disability and social stratification. British fournal of Sociology 1991;42:557-80.

14 Hanford HA, Mayes SD, Bixler ED, et al. Personality traits of haemophilic boys. $\mathcal{F}$ Dev Behav Pediatr 1986;7:224-9.

15 Koivusilta L, Rimpelä A, Rimpelä M. Health status: does it predict choice in further education ? F Epidemiol Community Health 1995;49:131-8.

16 van der Lucht F, Groothoff J. Social inequalities and health among children aged $10-11$ in the Netherlands: causes and among children aged 10-11 in the Netherlands:
consequences. Soc Sci Med 1995;40:1305-11.

17 Glendinning A, Love JG, Hendry LB, et al. Adolescence and health inequalities: extensions to Macintyre and West. Soc health inequalities: extension
Sci Med 1992;35:679-87.

18 Glendinning A, Shucksmith J, Hendry L. Social class and adolescent smoking behaviour. Soc Sci Med 1994;38;144960.

19 Glendinning A, Hendry L, Shucksmith J. Lifestyle, health and social class in adolescence. Soc Sci Med 1995;41:235-48.

20 Aaro LE, Wold B, Kannas L, et al. Health behaviour in schoolchildren. A WHO cross-national survey. A presentation of philosophy, methods and selected results of the first survey. Health Promotion 1986;1:17-33.

21 Nutbeam D, Aaro L, Catford J. Understanding childrens' health behaviour: the implications for health promotion for young people. Soc Sci Med 1989;29:317-25.

22 Hammarström A, Janlert U, Theorell T. Youth unemployment and ill health: results from a 2-year follow-up study. Soc Sci Med 1988;26:1025-33.

23 Olafsson O, Svensson PG. Unemployment-related lifestyle changes and health disturbances in adolescents and
children in the western countries. Soc Sci Med 1986;22: children

24 Power C, Manor O, Fox AJ. Health and class: the early years. London: Chapman and Hall, 1991

25 Kuh DJL, Cooper C. Physical activity at 36 years: patterns and childhood predictors in a longitudinal study. $\mathcal{f}$ Epidemiol Community Health 1992;46:114-19.

26 Illsley R. Social class selection and class differences in relation to stillbirths and infant deaths. BMF 1955;ii:1520-4.

27 Helakorpi S, Berg MA, Uutela A, et al. Health behaviour
28 Blane D, Davey Smith G, Bartley M. Social selection: what does it contribute to social class differences in health? Sociol Health Illness 1993;15:1-15.

29 Wolfe BL. The influence of health on school outcomes. A multivariate approach. Med Care 1985;23:1127-38.

30 Kunst AE, Mackenbach JP. The size of mortality differences associated with educational level in nine industrialized countries. Am F Public Health 1994;84:932-7.

31 Hosmer DW Jr, Lemeshow S. Applied logistic regression. New York: John Wiley, 1989.

32 Agresti A. Categorical data analysis. New York: John Wiley, 1990.

33 Dixon WJ, ed. BMDP statistical software manual. Berkeley: University of California Press, 1992

34 Rönkä A, Pulkkinen L. Accumulation of problems in social functioning in young adulthood: A developmental approach. F Pers Soc 1995;69:381-91.

35 Pulkkinen L. Life-styles in personality development. Special issue: Longitudinal research and personality. European fournal of Personality 1992;6:139-55.

36 Willis P. Learning to labor. New York: Columbia University Press, 1977.

37 Pohjanpää $\mathrm{AKJ}$, Rimpelä $\mathrm{AH}$, Rimpelä $\mathrm{M}$, et al. Is the strong positive correlation between smoking and use of alcohol consistent over time ? - A study of Finnish adolescents from 1977-1993. Health Education Research: Theory and Practice 1997;12:125-36.

38 Isohanni $\mathrm{M}, \mathrm{Oja} \mathrm{H}$, Moilanen I, et al. The relation between teenage smoking and drinking, with special reference to non-standard family background. Scand $f$ Soc $\mathrm{Med}$ 1993;21:24-30.

39 Coleman J. The adolescent society. New York: Free Press, 1961.

40 Pietilä AM, Rantakallio P, Läärä E. Background factors predicting non-response in a health survey of Northern Finnish young men. Scand F Soc Med 1995;23:129-36.

41 Carr-Hill RA. Time trends in inequalities in health. $f$ Biosoc Sci 1988;20:265-73.

42 Nyström Peck AM. Childhood environment, intergenerational mobility, and adult health-evidence from Swedish data. F Epidemiol Community Health 1992;46:71-4.

43 Power C, Fogelman K, Fox AJ. Health and social mobility during the early years of life. Quarterly fournal of Social Affairs 1986;2:397-413.

44 Bielicki T, Charzewski J. Body height and upward social mobility. Ann Hum Biol 1983;10:403-8.

45 Cernerud L. Are there still social inequalities in height and body mass index of Stockholm children ? Scand 7 Soc Med $1994 ; 22: 161-5$.

46 Macintyre S. Social correlates of human height. Sci Prog 1988;72:493-510

47 Ehrhardt AA, Meyer-Bahlburg HF. Psychosocial aspects of precocious puberty. Horm Res 1994;41:30-5

48 Kangas O. The politics of social rights. Studies on the dimensions of sickness insurance in OECD countries. Swedish Institute for Social Research 19. Edsbruk: Akademitryck AB, 1991.

49 Taylor S, Repetti RL. Health psychology: what is an unhealthy environment and how does it get under the skin. Annu Rev Psychol 1997;48:411-47.

50 Erikson R, Jonsson JO. Intruduction. Explaining class inequality in education: The Swedish test case. In: Erikson $\mathrm{R}$, Jonsson JO, eds. Can education be equalized? The Swedish case in comparative perspective. Oxford: Westview Press, 1996.

51 Lundberg $\mathrm{O}$. The impact of childhood living conditions on illness and mortality in adulthood. Soc Sci Med 1993;36: 1047-52.

52 Aaro L, Laberg J, Wold B. Health behaviours among adolescents: towards a hypothesis of two dimensions. Theory and practice. Health Education Research 1995;10: 83-93. 